de o desenvolvimento de novos materiais para aplicações médicas, células solares, fotorremediação de águas residuais, terapia fotodinâmica, manipulação de nanoestruturas, mimetização de biofuncionalidades e recuperação de objetos de arte. Todas as sessões, orais e em painel, tiveram uma elevada participação, o que permitiu uma discussão aprofundada e participada dos temas apresentados.

Nesta edição do IUPAC Symposium on Photochemistry foram vários os prémios atribuídos, sendo de salientar: a medalha Porter, a Thomas Meyer (Figura 2), da Universidade da Carolina do Norte (E.U.A.); o prémio $E P A$, a Karl Borjesson, da Universidade de Chalmers (Suécia); o prémio Langmuir (ACS), para a melhor apresentação oral de jovens fotoquímicos, atribuído a Danielle Wilson (Canadá); a melhor apresentação em painel (prémio IUPAC), atribuída a Waheed Saban (África do Sul) e a Joanna Malicka (Bélgica); e a melhor apresentação em painel de estudantes de doutoramento, atribuída a Karel

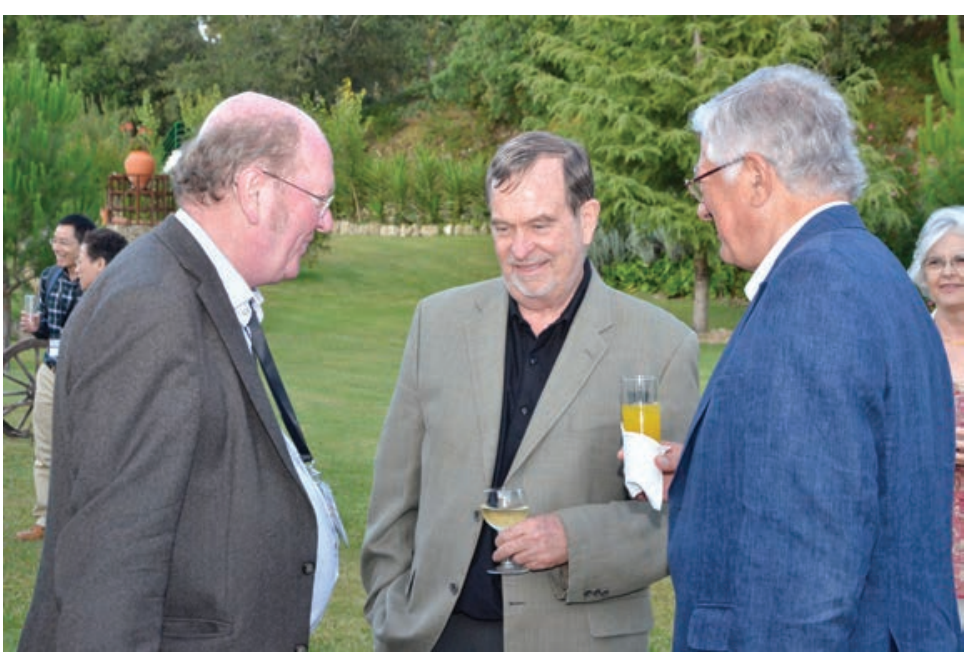

Figura 2 - Aspeto do convívio informal que precedeu o banquete do Simpósio. Profs. Hugh Burrows (UC), Thomas Meyer (Universidade da Carolina do Norte e galardoado com a medalha Lord George Porter) e Sebastião Formosinho (UC)

Goossens (Bélgica) e a Giorgio Pariani (Itália).

A Organização do Simpósio contou ainda com o apoio dos seguintes patrocinadores: Bluepharma, Caixa Geral de Depósitos, Edinburgh Instruments, Elsevier, FCT, Gilden Photonics, Hamamatsu, Langmuir, M.T.
Brandão, Paralab, Photochemical \& Photobiological Sciences, PicoQuant e Springer.

O XXV IUPAC Symposium on Photochemistry será em Bordéus em 2014.

Hugh Burrows e Artur Valente

(burrows@ci.uc.pt, avalente@ci.uc.pt) Comissão Organizadora

\title{
International Symposium on Metal CompleXes (ISMEC2012)
}

A edição de 2012 do International Symposium on Metal Complexes (ISMEC2012) realizou-se em Lisboa, de 18 a 22 de junho de 2012, na Fundação Calouste Gulbenkian, e teve como objetivo principal a apresentação e a discussão dos mais recentes e importantes desenvolvimentos e inovações nas diversas áreas relacionadas com os complexos metálicos. A presente edição deste simpósio é também o XXIII Italian-Spanish Meeting Thermodynamics of Metal Complexes. Contudo, como ao longo dos últimos anos este formato de encontro anual tem assistido a um enorme incremento no interesse e número de participações de cientistas a nível mundial, na edição de 2010, o Grupo Italiano-Espanhol de termodinâmica de complexos metálicos decidiu a sua internacionalização e abertura a novas áreas. Assim, foi decidido estabelecer o "European Group of Thermodynamics of Metal complexes", assim como o acrónimo ISMEC para International Symposium on Metal Complexes.
A realização do ISMEC2012 em Lisboa surge como a primeira edição do simpósio realizada fora de Espanha ou Itália. Esta edição emerge como um marco e um passo em frente na internacionalização do ISMEC, tendo resultado num aumento de cerca de $100 \%$ relativamente ao número usual de participantes. A conferência contou com a participação ativa de mais de 200 participantes (Professores, Investigadores e Estudantes) originários de 27 países, a maior parte deles Europeus (Alemanha, Áustria, Bélgica, Bulgária, França, Espanha, Hungria, Itália, Letónia, Polónia, Portugal, Reino Unido, República Checa, Roménia, Rússia, Suíça e Turquia) e 10 países não Europeus (Africa do Sul, Argélia, Argentina, Austrália, Brasil, Canadá, China, Estados Unidos da América, Japão e Uruguai).

Esta opção estratégica na evolução do simpósio ISMEC teve por objetivo fomentar o intercâmbio de novas ideias e o aumento de projetos de colaboração em novas áreas de ponta relacionadas com a termodinâmica de complexos metálicos, tendo sido dada especial ênfase à ligação entre a investigação científica fundamental e a sua inovação associada à larga gama de aplicações, especialmente orientadas para fins ambientais e biomédicos.

Assim, no âmbito do ISMEC2012, foram aceites e discutidas apresentações que se incluíram nos vários tópicos abaixo descritos, embora especialmente focados na química dos complexos em solução e suas aplicações:

- Solution equilibrium and coordination chemistry

- Metal complexes of biological and environmental interest

- Supramolecular chemistry

- Metal-complex interactions with biomolecules

- Chemistry and cultural heritage

- Nanostructured metal complexes 


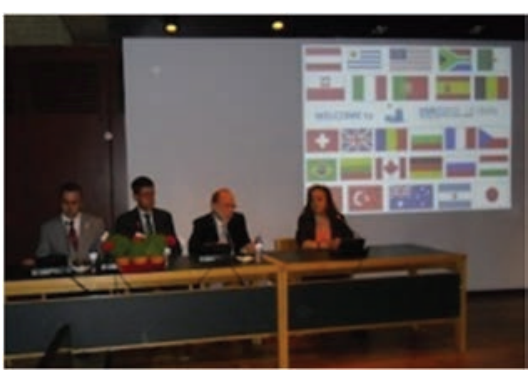

Cerimónia de abertura

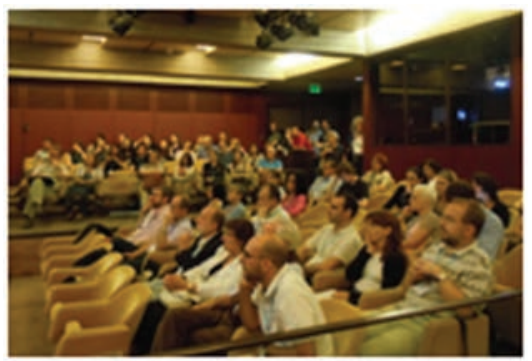

Vista parcial da audiência (A3-FCB)

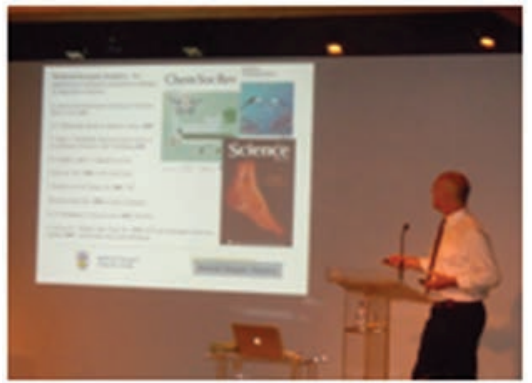

Chris Orvig (UBC, Canadá)

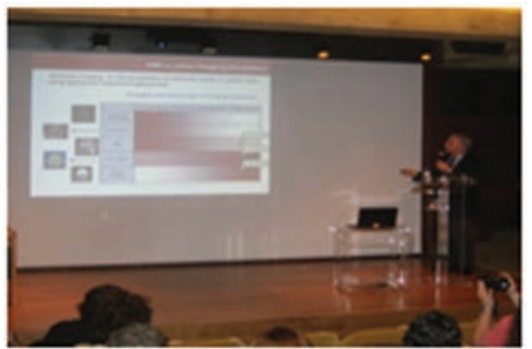

Carlos Geraldes (UC, Portugal)

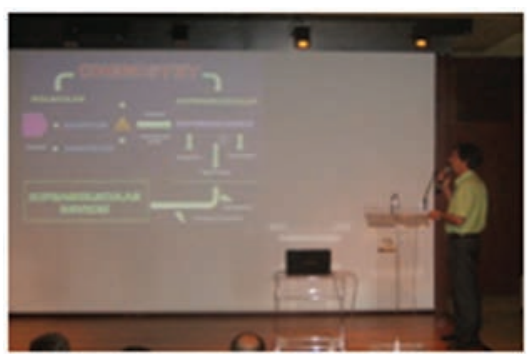

E. García España (UV, Espanha)

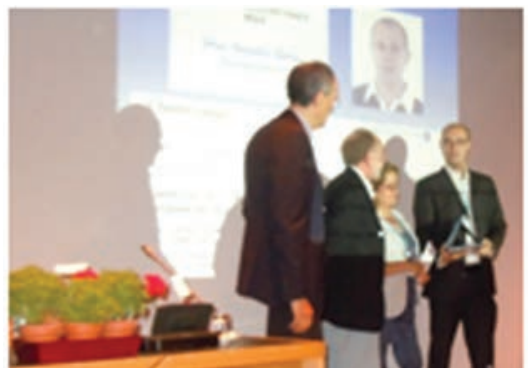

Entrega do Prémio Pullidori (J. González García)
- Metals in diseases: transport, homeostasis and toxicity

- Metal-based drugs: therapy and diagnosis

- Metalloenzymes: metal binding and models

- Analytical methods and sensors based on metal complexes

- Computational modeling

A agenda da conferência incluiu 5 Lições Plenárias, 10 Lições Orais Convidadas (Keynotes), 51 Comunicações Orais (selecionadas pela organização e apresentadas em 2 sessões paralelas) e 114 apresentações em Painel, um Prémio Pulidori, e ainda uma Mesa Redonda com o Grupo ISMEC.

O Comité Organizador do ISMEC2012 convidou 15 reputados investigadores e cientistas internacionais para as lições plenárias e convidadas, cujos temas exibiram uma resposta perfeita ao desafio colocado pela organização, além de promoverem debates e discussões de elevado nível científico. Descrevem-se a seguir os títulos das 5 Lições Plenárias:

- "Redox metals in neurodegenerative diseases, and therapeutic perspectives", Robert R. Crichton, University Catholique de Louvain, Bélgica

- "Metal ion selective sequestering agents, with selective properties", Kenneth N. Raymond, University of California, Berkeley, E.U.A.

- "Medicinal inorganic chemistry", Chris Orvig, University of British Columbia, Vancover, Canadá

- "Metal-based chelates and nanosystems for multimodal molecular imaging applications", Carlos F.G.C. Geraldes, Universidade de Coimbra, Portugal

- "Luminescent silica nanoparticles: extending the frontiers of brightness", Luca Prodi, University of Bologna, Itália

Foram ainda apresentadas as seguintes Lições Keynote:

- "The chemistry behind the use of bioassays to assess metal toxicity: $\mathrm{pH}$ influence, complexation equilibria", Isabel Villaescusa, University of Girona, Espanha
- "Structural and thermodynamic aspects of thiol binding to metal ions in excentric proteins", Henryk Kozlowski, University of Wroclaw, Polónia

- "Metal complexes defining aluminium's exposome", Christopher Exley, University of Keele, Reino Unido

- "Modelling of molecular properties. Fundamental principles and case studies with transition metal complexes", Peter Comba, University of Heidelberg, Alemanha

- "Cation, anion and ion-pair binding with branched polyamines", Antonio Bianchi, University of Florence, Itália

- "Macrobicyclic architectures for recognition of anions and metal ions", Rita Delgado, ITQB/Universidade Nova de Lisboa, Portugal

- "Metal ion and anion coordination chemistry of pyrazole azamacrocycles, Enrique García-España, University of Valencia, Espanha

- "Interaction of hydroxamic acids with metal ions: from simple complexes to metallacrowns", Fernando Secco, University of Pisa, Itália

- "Mechanistic modelling of actinides and lanthanides extraction by ionic liquids: a first step towards a general model", Isabelle Billard, IPHC/DRS, Strasbourg, France

- "Chemical speciation in environment and biomedicine: examples to technological development", Manuel Valiente, University Autònoma of Barcelona, Espanha

É de salientar que todos os resumos aceites para apresentação no ISMEC2012 estão publicados online num livro da série "Acta of ISMEC Symposia, Vol 2 (ISSN 2239-2459, http://mat520.unime.it/ismecacta), permitindo assim uma rápida divulgação dos mais recentes desenvolvimentos de investigação científica apresentados e discutidos no simpósio. Por outro lado, reconhecendo a grande importância da internacionalização do ISMEC, concretizada na presente edição, o prestigiado jornal internacional Dalton Transactions (RSC) associou-se a este evento científico, tendo oferecido a publicação de um volume especial temático dedicado a este 
simpósio e intitulado "The chemistry and applications of metal complexes", o qual incluirá uma seleção dos artigos mais relevantes apresentados no âmbito deste congresso.

A presente edição do ISMEC (ISMEC2012), foi organizada pelo Instituto Superior Técnico da Universidade Técnica de Lisboa, em cooperação com a Sociedade Portuguesa de Química, tendo como Presidente da Comissão Organizadora a Prof. Maria Amélia Santos. O Comité Científico Internacional (CCI) do ISMEC2012 foi incumbido de selecionar o recipiente

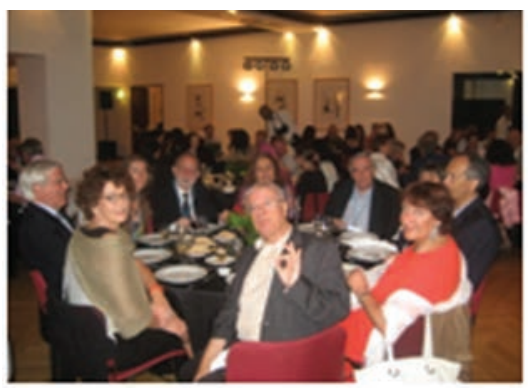

Jantar social (CCB) do Prémio Pulidori ( $5^{\text {th }}$ Edition), de entre 30 concorrentes, jovens investigadores participante no ISMEC2012 e autores de um artigo original publicado no período 2010-2012. O premiado deste ano foi Jorge González García, da Universidade de Valencia, com um artigo intitulado "Kinetics of $\mathrm{Zn}^{2+}$ complexation by a ditopic phenanthroline-azamacrocyclic scorpiand-like receptor", Chem. Commun. 2012, 48, 1994-1996. Um resumo alargado deste trabalho será também publicado na revista "La Chimica e L'industria", o jornal oficial da Sociedade Italiana de Química.

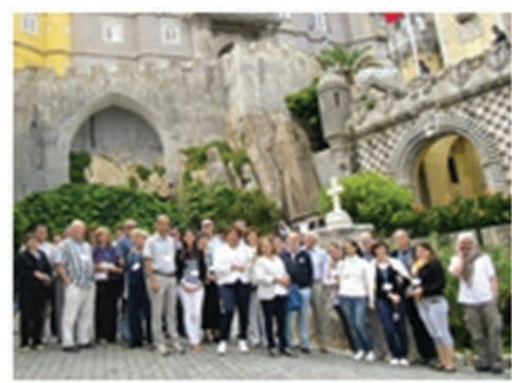

Visita a Sintra (grupo parcial)
A próxima Edição do ISMEC (ISMEC2013) realizar-se-á em Burgos (Espanha), em junho de 2013. O ISMEC2012 contou com o apoio institucional do IST, SPQ, CQE, FCG, a colaboração das empresas CGD, BPI, HOVIONE, ILC, TAP, Labor Spirit, Cruz-Porto, Hotel Açores e ainda dos departamentos de turismo das CM Lisboa e CM Sintra.

Maria Amélia Santos

(masantos@ist.utl.pt)

Presidente da Comissão Organizadora do ISMEC2012

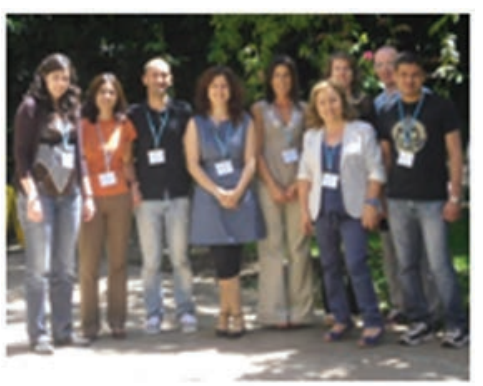

Comissão Organizadora

\section{Simpósio de Homenagem ao Prof. Doutor Fernando Ramôa Ribeiro}

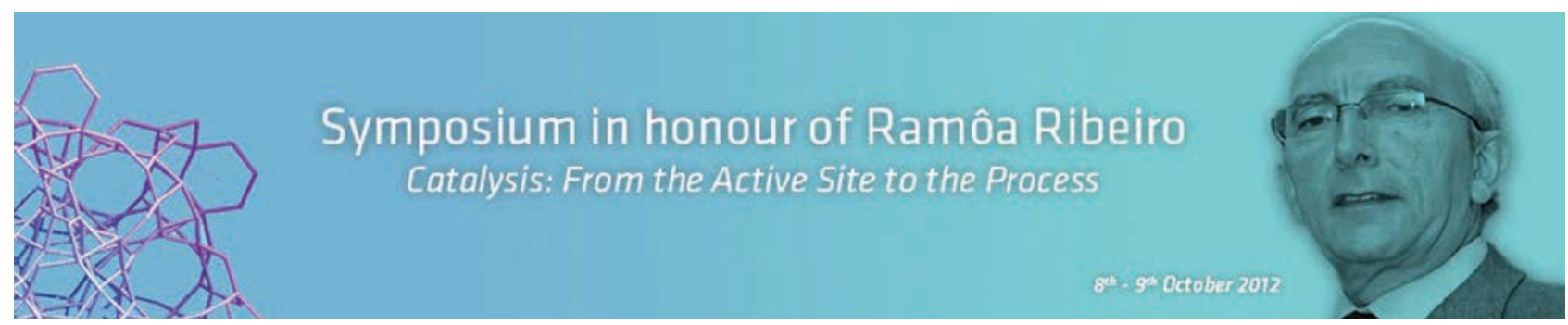

Decorreu, nos passados dias 8 e 9 de outubro, no Salão Nobre do Instituto Superior Técnico, o Simpósio de Homenagem ao Prof. Fernando Ramôa Ribeiro, subordinado ao tema "From the Active Site to the Process", um evento que teve o apoio da Sociedade Portuguesa de Química.

Fernando Ramôa Ribeiro, falecido em 29 de agosto de 2011, dedicou toda a sua vida científica à catálise, e em particular à catálise por zeólitos, domínio em que criou um grupo de investigação dinâmico, com uma elevada produtividade, quer a nível de formação de recursos humanos, em particular ao nível de doutoramentos, quer ao nível de publicações e de organização de encontros internacionais. Foi este gru- po de investigadores que decidiu organizar este Simpósio como forma de homenagear a memória deste Professor e Cientista recentemente falecido.

A atividade científica de Fernando Ramôa Ribeiro deu origem a uma vasta rede de contactos que, de certa forma, se reuniu neste simpósio em sua memória. A sessão de abertura contou com a presença, entre outras personalidades, do Ministro da Educação e Ciência, do Presidente do Conselho Geral e do Reitor da UTL, e do Presidente do IST que, para além da representação institucional, trouxeram os seus testemunhos do relacionamento com o Prof. Ramôa Ribeiro ao longo da sua carreira na área do Ensino Superior e da Ciência em Portugal. A ses- são contou ainda com a presença do Embaixador de França em Portugal, num reconhecimento ao trabalho desenvolvido por Ramôa Ribeiro em prol da colaboração científica e académica entre Portugal e França.

No plano científico, os trabalhos dividiram-se entre um conjunto de comunicações por destacados membros da comunidade científica ligada à catálise a nível Europeu e de Portugal, e um conjunto de apresentações ligadas a empresas da área da química que em Portugal e em França colaboraram com o Prof. Ramôa Ribeiro e a sua equipa.

As apresentações científicas contaram com personalidades como Michel 